\title{
Critical care nurses' perceptions of stress and stress-related situations in the workplace
}

\author{
S Moola, D Litt et Phil \\ D Litt et Phil graduate, University of South Africa
}

VJ Ehlers, D Litt et Phil

Professor, Department of Health Studies, University of South Africa

SP Hattingh, D Litt et Phil

Associate Professor, Department of Health Studies, University of South Africa

Keywords:

burnout, consciousness awareness, critical care nurses, resiliency, job-related experiences, stress management

\section{Correspondence address:}

Prof VJ Ehlers

Department of Health Studies

POBox 392

Unisa

0003

Tel : (012) 429-67321(w)

Fax: (012) 429-6688(w)

Cell: 0845873303

E-mail: ehlervj@unisa.ac.za

\section{Abstract: Curationis 31(2): 74-83}

Critical care nurses (CCNs) experience stressful situations in their daily working environments. A qualitative research approach (exploratory, descriptive and contextual) was used to explore and describe the stressful situations experienced by critical care nurses in the Tshwane metropolitan are of South Africa. Focus group interviews were conducted with critical care nurses.

Data was generated by means of focus group interviews. The results revealed CCNs' perceptions and experiences about stressful events, factors contributing to stress in the critical care environment, as well as their needs for support systems.Critical care nurses experience stressful situations in their daily working environments. The question arises for nurses: are there adequate support systems in the critical care environment and what are critical care nurses doing to maintain their own health and well-being? Facilitating conscious awareness among critical care nurses could enhance their resiliency and their hardiness, strengthening their coping capacities in stressful working situations. The contextual framework adopted for this research was the Neuman Systems Model. A qualitative research approach (exploratory, descriptive and contextual) was used to explore and describe the stress experienced by critical care nurses. Focus group interviews were conducted with critical care nurses and individual interviews with nurse managers. The results revealed their perceptions and experiences about the effects of stress in the critical care environment, as well as some of their coping strategies. The recommendations include that stress management programmes should be implemented and evaluated; debriefing services should be available to CCNs, inservice education programmes should address raising CCNs' consciousness awareness and enhance their resiliency skills. Effective communication systems should be established between managers and CCNs to address inconsistencies as they arise, including critical shortages of staff and equipment. 


\section{Introduction}

Owing to the highly technical nature of the critical care environment in which CCNs work, and the critical incidents which they encounter, large numbers of critical care nurses might be in danger of developing post-traumatic stress disorder. This makes it imperative that they develop conscious awareness as a basic prerequisite for stress management and enhanced resilience behaviour. Conscious awareness is gained when an inner sense of behaviour enhances selfcontrol and personal autonomy is regained through behaviour modification (Taylor, 1999: 321). The aim of conscious awareness is to achieve self-awareness of present thoughts and feelings, to accept those feelings experienced and to own them (Müller, 1998:33). Developing resilience is one process which could assist CCNs to attain and maintain desirable levels of conscious awareness. Realistic conscious awareness is a significant aspect in coping with and adapting to change within the self (Müller 1998:33).

Stressful events are an inevitable part of life. Many people are able to cope with stresses depending on the severity of the stress. However the severity of the stress does not always predict a resultant adjustment disorder. Most people under stress do not develop mental disorders, though possibly a vulnerability to them. Stresses differ in degree, quantity, duration, reversibility, environment and personal context. Stress that is chronic and ongoing may result in a chronic disorder. Nurses who work in highly stressful situations are constantly under pressure and are vulnerable to a variety of symptoms in reaction to the stress. Over time the exposure to stress and trauma may induce both physical and emotional signs described as "burnout" (Cudmore, 1996:20).

\section{Background information}

Professional burnout is a phenomenon that can occur in the life of a critical care nurse $(\mathrm{CCN})$. Internal and external stresses are inherent in the critical care environment. This environment involves stressful critical situations relating to role conflict, role ambiguity, qualitative and quantitative work overload, rapid decision making and a speedy delivery of care. CCNs experience suffering as affecting their integrity and wholeness, and their ability to carry out their perceived roles. They practise in the face of moral incongruity on a daily basis. Thus CCNs might have difficulty in meeting their obligations to themselves as well as to their patients. These persistent difficulties could evolve into distress. The starting point for growth is knowledge about the present situation. CCNs must become aware of how they see themselves and how they act on those perceptions (Bosek De Wolf, 1999:12-13).

Bailey (1985:47) points out that CCNs who reach the limits of their adaptive capabilities are unable to cope with posttraumatic stress and often leave the critical care environment. The focus of this article is that CCNs need to confront the different situations in which they find themselves. Effective coping entails accurate perceptions, knowledge, courage and cognitive appraisals. The critical care environment must be effectively assessed in order to establish a starting point for promoting coping resources. A major part of this assessment must be directed at the $\mathrm{CCN}$, who must recognise signs and symptoms before any type of intervention can be implemented. CCNs can identify signs and symptoms of post-traumatic stress by becoming attentive to signals of physiological arousal, but they might hide underlying stress responses (Muldary, 1983:124-126). Not all CCNs exposed to stressful situations suffer from burnout, presumably because some might be more resilient to stresses than others.

Deliberate self-monitoring of physical signs, thoughts and emotions enhances conscious awareness. Self-monitoring entails observational skills, which are applied inward to the "self" (Muldary, 1983:127) to help develop greater resilience.

\section{Problem statement}

While it is generally acknowledged that the critical care environment encompasses stresses, the precise jobrelated stresses encountered by critical care nurses need to be identified. Once these stresses have been acknowledged and addressed, remedies to address stressful situations could be identified and implemented to enhance the coping skills of critical care nurses, to improve the quality of patient care rendered and reduce the turnover rates among $\mathrm{CCNs}$.

\section{Research questions}

The following research questions guided the study:

- What stressful job-related incidents do CCNs experience?

- What coping strategies do CCNs use?

- How could the CCNs be helped to enhance their coping skills with stressful job-related experiences?

\section{Purpose of the research}

The purpose of this research was to identify CCNs' stressful job-related experiences, their coping strategies to address these stresses and to recommend ways in which these coping strategies could be enhanced.

\section{Assumptions}

The assumptions underlying this research included that $\mathrm{CCNs}$

- $\quad$ experience stressful job-related incidents

- $\quad$ might have some strategies for coping with stress

- $\quad$ enhanced coping strategies would enable CCNs to enjoy a better quality of personal and professional life and

- $\quad$ might contribute towards reducing the turnover rates of CCNs

\section{Objectives of the study}

The objectives of this study were to:

- describe CCNs' experiences stressful incidents

- $\quad$ identify the coping strategies used by $\mathrm{CCNs}$

- $\quad$ recommend ways in which CCNs' coping strategies could be enhanced.

\section{Definitions of terms used in the context of this study}

The definitions explain the way in which the following terms are used in the context of this study:

\section{Adaptation}

Monsen, Floyd and Brookman (1992:28) describe adaptation as the modification of behaviour to eliminate the stress experience and maintain balance and integrity. Adaptation maintains the balance between perceived demands and coping. Ineffective adaptation causes 
internal disorganisation

\section{Burnout}

The term "burnout" refers to a syndrome of emotional exhaustion, depersonalisation and reduced personal accomplishments occurring among professional persons such as nurses, rendering caring services. The burnout syndrome has five common characteristics, according to Maslach and Schaufeli (1993:1-18):

- Dysphoric symptoms such as mental or emotional exhaustion, fatigue and depression.

- Displaying mental and behavioural symptoms rather than physical symptoms, although some authors mention atypical physical complaints as well.

- $\quad$ Burnout symptoms are work related.

- The symptoms manifest themselves in "normal" persons who did not suffer from psychopathology previously.

- Decreased effectiveness and work performance occur because of negative attitudes and behaviour.

\section{Compassion fatigue}

Pfifferling and Gilley (2000:39) describe a form of burnout as "compassion fatigue", a deep physical, emotional and spiritual exhaustion accompanied by acute emotional pain. Compassion fatigue takes a toll, not on the health-care professionals only, but also on the workplace, causing a decrease in productivity, increased absenteeism and increased rates of staff turnover.

\section{Conscious awareness}

Conscious awareness is a process whereby human beings gain an awareness of their internal psychological processes (thinking, reasoning and feeling), obtaining access to their internal worlds and acquiring insight into their feelings and emotions. Conscious awareness requires the owning of thoughts and feelings in dealing with conflicting or distressing situations (Pollard 1994:727).

\section{Coping}

Coping is viewed as the process through which the individual manages the demands of the person/environment relationship that are appraised as stressful (Lazarus \& Folkman 1984). Problem-focused coping determines to what extent transactions are stressful (primary appraisal) and the options that are open to deal with the stressor (secondary appraisal).

\section{Critical care environment}

Clochesy, Breu, Cardin, Rudy and Whittaker (1996:xiii) describe the environment in which critical care nursing is practised as a collaboration of relationships, continuous learning, innovation, and shared expertise.

\section{Critical care nurses}

Critical care nurses (CCNs) are specialised nurses who have mastered knowledge about critical care nursing and about pertinent information from other disciplines. These highly competent and skilled nurses provide intensive care for patients requiring both close monitoring and critical care interventions (Clochesy et al., 1996:xiii).

\section{Post-traumatic Stress Disorder (PTSD)}

Should stress responses become prolonged, signs and symptoms of PTSD could occur. These include constant flashbacks, unwanted thought intrusions, moodiness, difficulty in concentrating, avoidance behaviour and restlessness, fatigue, sleep disturbances, anxiety and depression. If these disturbances continue, the person's ability to function will be adversely affected (Bell, 1995:37).

\section{Resilience}

Strümpher (1995:87) defines resilience as a pattern of psychological activity which includes a need or motivation to be strong in the face of adversity or inordinate demands, especially stressful and traumatic experiences.

\section{Stress}

Although there are numerous definitions of stress, this study accepted the definition of the Concise Oxford Handy Dictionary (1991:903) as demands on physical or mental energy that cause tension.

\section{Stressors}

Neuman (1995:22) defines stressors as tension-producing stimuli which result in disequilibrium within the internal, external and created environments. The effect of the stressor in any type of environment is mitigated by the number, nature and intensity of stressors; and the timing, occurrence, and conditions of well-being and adaptive ability of human beings within the environment. The environmental stressors include intra-, inter- and extrapersonal stressors:

- Intrapersonal stressors would be those within the $\mathrm{CCN}$ him/ herself, such as adverse emotions.

- Interpersonal stressors would be forces that exist outside the boundaries of the $\mathrm{CCN}$, for example, interpersonal relationships with ether health care workers, with patients and their families/friends.

- Extrapersonal stressors may be experienced by the $\mathrm{CCN}$ due to adverse factors in the environment, such as respirators which malfunction or interruptions in the electricity supply.

\section{Significance of this research}

Descriptive research about the use of techniques that facilitate reflection, conscious awareness, resilience techniques, debriefing and counseling may enhance nurses' coping skills in clinical areas (Wilkinson 1999:39). Enhanced coping skills of CCNs might help to reduce the turnover rates among this group of specialised nurses, reducing healthcare costs and improving the quality of care rendered to critically ill patients.

\section{Research design}

The research strategy comprised an exploratory (Mouton \& Marais, 1990:43), descriptive (Burns \& Grove, 1999:28), qualitative (Burns \& Grove, 1999:411), contextual (Mouton \& Marais, 1990:43) design.

The researchers departed from a point of reference of not knowing, and thus used exploratory methods to gain information through focus groups (Mouton \& Marais, 1990:43). Adescriptive study is structured and organised according to saturated themes which will provide relevant information (Burns \& Grove, 1999:411). This research aimed at identifying ways in which CCNs' levels of coping skills could be enhanced in order to reduce the potential impact of stressful job-related experiences on the 


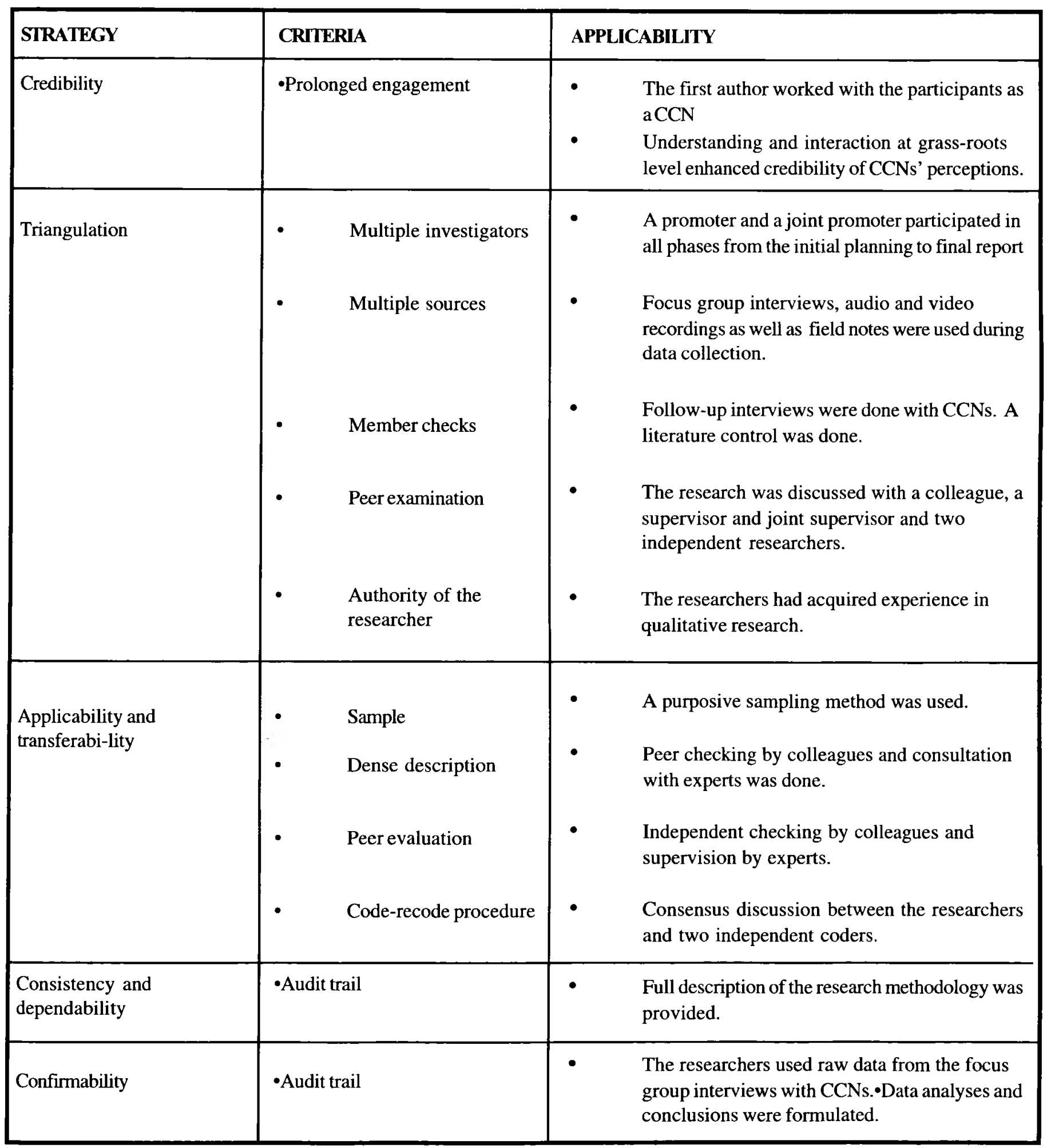

(Guba \& Lincoln,1985:306)

CCNs. Burns and Grove (2001:808) define qualitative research as: "A systematic, interactive, subjective approach used to describe life experiences and give them meaning". The focus group interviews attempted to obtain information about CCNs' stressful experiences in CCUs. A context is a particular set of conditions within which the action/interaction strategies are taken (Strauss \& Corbin 1990:29). This study was contextual in that it dealt with CCNs and the critical care environment within which the $\mathrm{CCNs}$ operated.

\section{Research population and sample Sampling}

The target population comprised CCNs working in five hospitals in the Tshwane metropolitan area, because their specific characteristics, similar interests and experiences were significant to this research (Brink 1996:132; Polit \& Hungler 1993:173-174; Strauss \& Corbin 1990:182). A nonprobability purposive sampling approach was used (Parahoo 1997:232) to select 10 participants, five for each focus group interview.

Participants had to meet the following criteria:

- $\quad$ They had to be employed full time or part time as CCNs in one 
of the five participating hospitals in the Tshwane metropolitan area.

- They had to have a diploma Honours or Master's degree in critical care nursing.

- Participants had to be registered with the SANC as critical care nurses

- $\quad$ Each participant had to give informed consent to participate in the research.

- $\quad$ Participants had to be able to converse in English during the focus group interviews.

\section{Trustworthiness}

See table 1.

\section{Data Collection Data Collection}

Participants who met the sampling criteria participated in two focus group interviews, consisting of five participants which were recorded by audio tape and video camera, and transcribed verbatim. Field notes were also taken. The following questions were posed to the participants:

Do you experiences stress in your work situation? Tell me about it. (This served as the opening question to initiate interaction among the participants).

- How do you know that you are experiencing severe stress? (This was the transition question linking the introductory question to the following analysing questions).

- What happens in the work environment? What happens in your personal environment? How do you handle stress in your work situation? How do you assume responsibility for your "self-care"?

- $\quad$ The summary questions, based on the participants'

discussions, were: What does your employer do to help you cope with stress? How do you feel about the employer's assistance in this regard?

- $\quad$ The final questions, asked at the end of the focus group discussion, were: Is there a need for stress management programmes in your hospital? How do you think CCNs could be helped to cope with stress in

\section{Data analysis Data analyses}

The data obtained by a descriptive approach were analysed, by using a computer package for the analyses of qualitative non numerical unstructured data indexing searching and theorising (NUD*IST 4). The participants' verbatim statements, as transcribed from the audiotapes, were analysed. In cases of uncertainty, the statements on the video recordings were correlated with those from the audiotapes. Data within the same category were then grouped and subcategories were developed. The data were organised by identifying meaningful units which were categorised or coded (Cresswell, 1994:1). Data were validated by moving backwards and forwards between the raw data and the categorised data in NUD*ST 4. Data were then compared in order to identify common and unique themes and patterns (Burns \& Grove, 1999:24).

Two nurse researchers independently developed the categories and subcategories. Thereafter these two researchers jointly decided which categories and sub-categories to accept and which to combine. A summary of the major categories, sub-categories and sub-sub categories is provided in table 2

\section{Research results}

Table 2 portrays the major categories, and sub categories into which the data were grouped.

\section{Participants' perceptions about stressful job-related situations}

The reported perceptions of stress among CCNs were grouped into subcategories of eustress versus distress, stress measurement, physicial and emotional symptoms of stress, the influence of stress on different personality types and the inability to function.

\section{Eustress versus distress}

Participants vaguely described eustress as good stress implying the ability to cope and distress as bad stress and being unable to cope in stating:

... for me that stress is a good stress I live on that stress, on that adrenaline. I think there is a difference between good stress and bad stress, you keep deadlines, you keep going.
I think bad stress is what comes out in you physically, you know you scream at people, you are irritable.

Selye (1974:10) maintains that a certain level of stress is essential for people to function. Moderate amounts of stress could be growth-producing challenges for many people. However, excessive stress could produce many emotional and physical symptoms, accounting for more than $80 \%$ of all visits to health care professionals (Everly \& Lating, 1995:3). One participant recognised that stress causes her to become irritable and .. scream at people...

\section{The inability to measure stress levels}

CCNs' perceptions of stress indicate that stress was difficult to "measure" and that stress as such could not be understood nor controlled in terms of the amount of stress experienced. One participant stated:

... how do you measure stress you know, you can't say but you only work twice a week you can 't have stress. You work six days a week, you can have stress .... but how do you measure stress?

Although it is acknowledged that it might be problematic to "measure" stress (Finnegan, 1998:218; Van Servellen \& Leake, 1993:169), CCNs' levels of stress might be cumulative if they cannot work through one stressful event (such as the death of patient) before the next one occurs (Laws \& Hawkins 1995:32). At least one participant agreed with this standpoint when she stated:

You get a tolerance for your stress level and you must try not to exceed that... so don't think that stress is the problem, but the amount. Ongoing stress can be a problem.

\section{Physical and emotional symptoms of stress}

Physical and emotional symptoms were described by the participants as negative and were highlighted as frustration, irritability, anger, emotionally fearful, being over-sensitive and temperamental. Due to the stress... there's ten times more friction ... people are at each others throats, and that's the worst because you hurt a person because of the frustrations you've got inside of you, not that you have anything against the person.......

... you damage your own persons around you... 
Table 2: Summary of major categories, subcategories and sub-sub categories

\begin{tabular}{|c|c|c|}
\hline \multicolumn{2}{|c|}{ CATEGORY } & Subcategory \\
\hline (1) & Perceptions about stress & $\begin{array}{ll}- & \text { Eustress or distress } \\
\text { - } & \text { Stress measurement } \\
\text { - } & \text { Physical and emotional symptoms } \\
\text { - } & \text { Personality type } \\
\text { - } & \text { Inability to function }\end{array}$ \\
\hline (2) & Stress experiences & $\begin{array}{l}\text { - Critical care environment } \\
-\quad \text { Physical environment } \\
\text { - } \quad \text { Psychological environment } \\
\text { - } \quad \text { Inevitability } \\
\text { - }\end{array}$ \\
\hline (3) & Needs of critical care nurses & 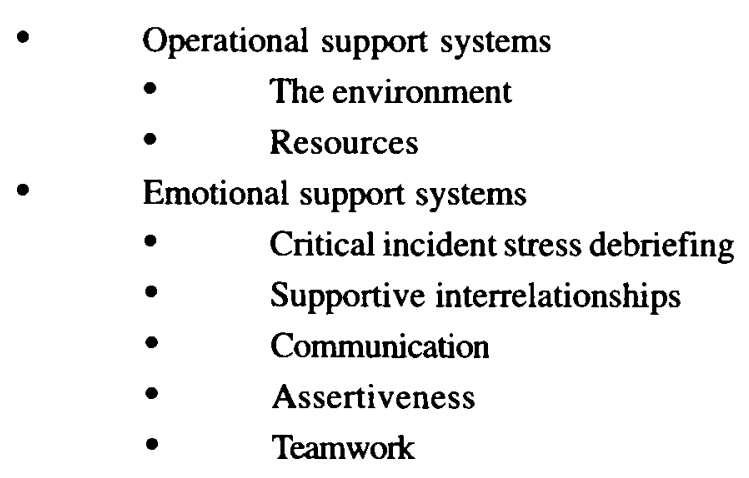 \\
\hline (4) & $\begin{array}{l}\text { Contributory factors to stress in the } \\
\text { critical care environment }\end{array}$ & $\begin{array}{ll}\text { - } & \text { Interpersonal relationships } \\
\text { - } & \text { Patient profile } \\
\text { - } & \text { Workload } \\
\text { - } & \text { Demands } \\
\text { - } & \text { Lack of trained personnel } \\
\text { - } & \text { Shift work } \\
\text { - } & \text { Absenteeism } \\
\text { - } & \text { Family factors } \\
\text { - } & \text { Doctor-nurse relationships } \\
\text { - } & \text { Cultural diversity }\end{array}$ \\
\hline (5) & Effects of stress & The perception of control \\
\hline
\end{tabular}

... the temper gets shorter, one gets more
weepy ...

They are highly stressed and... sensitive, over-sensitive.

It must come out, burst or break out....your behaviour must show that you are having these feelings.

You don't know who's where anymore and you have to keep your head and not forget anything, please don't forget anything.

Appleton (1994:25) reported that CCNs experienced critical and emergency situations in many different ways. Emotional reactions to stress include fear, anger, anxiety and depression. If stressors are concerned with anger, then irritability, aggressive outbursts and withdrawal from others are experienced. Involuntary cognitive responses include memory and concentration difficulties (Baum, 1990:653).

\section{Personality type}

The participants indicated that personality types influenced CCNs' reactions to and coping strategies with stressful events. Rutter (1985:598) reported that personality traits such as 
hardiness, self-esteem, extroversion, a sense of coherence and maintaining an internal (versus an external) centre of control, impacted positively on persons abilities to cope with stressful situations. The following statements indicate that CCNs' personality types might have impacted negatively on their coping capacities

I withdraw totally, I lock myself in my room or in my home, see nothing, do nothing, almost a type of escape.

Everybody must have respect for each other, nurses can be so mean sometimes.

\section{The inability to function as a result of stress levels}

The inability to function generated inadequate direction and support.

There's other colleagues, there's patients that are waiting, screaming ... but if you scream you cause a lot of stress to other people, nobody understands what you need.

\section{Doctors become furious and angry.}

The burnout period, it's only the ashes that's left and now to try and fix a person ... they first wait and see that you're burnt out and then want to fix things.

These statements indicate that CCNs may be affected emotionally and physiologically, leading to decreased performance (Orasao \& Bacher 1996:115) and increased risk of suffering from burnout (Keijsers et al 1995:513). CCNs' inability to function might be increased by repeated stressful events. Herman (1992:10) explained that while the victim of a single traumatic event "... may say she is not herself since the event, the victim of chronic trauma may lose the sense that she has a self". Such chronic exposures to stressful job-related events, are portrayed in the following statement: It doesn't matter how much you try avoiding it...tomorrow it will be there, there will be a shortage of staff, there will be very sick patients, incapable staff... you have to handle this.

\section{Critical care nurses' experiences of stress}

CCNs' experiences of stress were grouped into the following subcategories: critical care environment (physical and psychological), frequency intervals of pressure, inevitability, circumstances and role uncertainty.

Critical care environment
Stressful experiences in a critical care environment called for immediate attention and decision making. Conflict and disintegration resulted from an unsupportive physical and psychological environment, as revealed in the following statements:

For me why must the stress be so bad at work?

The place is too big, it's an open venue.

There is stress in a six bed unit as well as with sick people. You've got no time to get to every individual

If there isn't support, if the sisters don't work together and help each other it becomes very stressful, especially with very sick patients.

However, positive experiences were also reported:

Fortunately I can say... she's a positive person, she's an approachable person, you don't battle to work with her and that made me feel so good.

Much stress was experienced when the CCNs had to work with unskilled personnel who lacked knowledge about various procedures and protocols. This resulted in work overload and additional stress for permanent CCNs, as indicated by the following quotations:

Basic things ...you have to show her exactly the same thing ...you show her the first time, the second time, the third time.

There's no time, I'm dealing with an emergency situation, I cannot teach you...

I think the whole problem here is we have too little permanent trained staff or permanent staff with experience.

..every time it's a different agency nurse, which also frustrates the doctors.

Goll-McGee (1999:8) describe the critical care unit as a challenge to every $\mathrm{CCN}$ within which to care for acutely ill patients while coping with stressful fast-paced and demanding clinical events.

This description aptly summarises the experiences revealed by the CCNs who participated in this study's focus group interviews.

The frequency of stressful job-related

\section{experiences}

$\mathrm{CCN}$ 's reported the frequency of stressful events in the workplace to be causing a steady build-up of stress, as stated:

especially those people who work a lot... those that work overtime, work five consecutive days...

You get tolerance for your stress levels and you must try not to exceed that.. so I don't think stress is the problem but the amount. Ongoing stress can be a problem.

\section{The inevitability of stress}

The inevitability of stress was attributed to changes that occur momentarily, are unpredictable and inevitable. The circumstances mentioned were absenteeism, the expectation that CCNs must cope in spite of staff shortages, that time is limited while the demands are numerous.

....if you've got no staff, you know, you've been told or been taught to cope...

And when you go home, I sometimes wake up, but not to think... goodness, I haven't done that or I should have told someone that ...

\section{Circumstances under which $\mathrm{CCNs}$ work}

The focus group participants raised concerns about the circumstances under which CCNS are expected to render expert services to critically ill patients.

There are days when you feel you cannot cope and this is not only because you yourself do not have confidence or knowledge, it is the circumstances.

Most of the stress I experienced in the ICU... was the circumstances, because you know people do not come to work.

\section{Role uncertainty}

CCNs have a multitude of roles to fulfil. Role uncertainty is experienced when student CCNs have to cope with the theoretical and practical environment. Work/family roles and role overload was the result of conflict.

If you take your stress home with you, it can cause a lot of problems.

I don't think it's worth taking the stress home.

They were prepared to listen to it, five months, six months, these things are carrying on for years. So the moment you start talking about it, you hear 'just shut up please, because we 're fed up'. 
The doctors place a heck of a lot more stress on us.

\section{The needs of CCNs}

The needs of CCNs include operational (including the environment) and emotional support systems.

\section{Operational support systems}

The critical care environment is one with long working hours and a shortage of personnel, with numerous potential stressful incidents. CCNs, who participated in the focus group interviews did not portray a supportive work culture nor a collaborative work environment. They don't see me as a human being.

... there was no one who supported me...

I took care of a man who was in an accident... he literally bled to death in my hands, there was nobody to support me.

If you admit a critically ill patient and there are very few seniors, too few hands, that is also very stressful.

You find yourself looking after a sick patient or a difficult patient and there's no one to come and help with admissions.

I think the whole problem is we have too little permanent trained staff or permanent staff with experience.

Cudmore (1996:122) describes the critical care environment as dealing with situations that range beyond usual human experience. Much stress was generated by nurses who lacked knowledge about procedures and protocols, particularly about those concerning electrocardiograms (ECGs), anti-clotting time procedures and medications.

\section{Emotional support systems}

These support systems encompass the needs for criticial stress debriefing, supportive interrelationships, communication, assertiveness and teamwork.

\section{Critical incident stress debriefing}

Most participants agreed that no emotional support was given and felt that inter-professional collaboration depended on specific supportive strategies.

There are no systems in place to support, say listen, hmm, you must go and talk to such a person who does proper counselling.

When I had a problem they told me it's my problem, it's not the unit, it's not the workload, it's me, myself.

Berk (1998:20) states that it is not the work environment, nor the individual, but their interaction, which is responsible for the type of stress experienced by workers in a specific situation. Debriefing and defusing support systems for CCNs should be accessible 24 hours per day (Everly \& Latting 1995:131) to help resolve critical incident stress, and cumulative prolonged stress reactions. This author also maintains that the integration of professional and peer interventions improves identification and clarification of emotions.

\section{Supportive interrelationships}

Teamwork involves the sharing of experiences which lead to reflective consciousness, "normalising" experiences and alleviating emotional reactions to stress (Ivey, Ivey \& SimekMorgan, 1997:197). Supportive programmes are offered irregularly in some hospitals. Professional support groups are perceived as a stress reducer. A few participants described supportive environments and supportive interrelationships.

There is no supportive process in working between colleagues.

At peer group level they could sort out problems.

Say for instance you worked with someone who died ... the other people on duty with you should support you.

I don't expect my unit manager to put out her hand to assist me, but it would be very nice if she came around now and again and said: "Hi, are you still $O K$ ?"

\section{Communication}

Communication and good human relations are important for coping in stressful situations. Participants experienced vulnerability by often having to cope without showing any emotion, tension or pressure.

If you want us to decrease the stress levels, in most of the situations, you should be able to accommodate each other. ...proper communication skills...how things are being said

\section{Assertiveness}

A few participants stated that they were not able to be assertive in the work environment because of victimisation.

They tell you at a later stage that you said this and this, and you did this and this and in the end it is taken completely out of context. So, you learn to rather keep quiet, to hold back more and more and put it away and you don't even try to cope with it.

\section{Teamwork}

CCNs described a lack of teamwork and supportive interrelationships.

It always comes back to teamwork...

People will not help you of their own free will ... you have to beg her and say, please do this for me...."

Patient profiles affect the demands made upon the nurses and the physical and psychological well being of the CCN.

Yes in the unit where we work...there are a lot of factors, sick patients their age groups and the patient's families.

Most participants experienced physical exhaustion, emotional, cognitive and behavioural changes, due to a heavy workload.

I feel drained. You build on, it's snowballing and...no one copes.

A diversity of emotions were experienced concerning the demands and the coping efforts needed for working in a critical care environment.

...You only have two hands!

Absenteeism from work was the only way out for some participants who could not cope, a low morale and self-esteem pressured an avoidance type of behaviour as their only option.

Sometimes I feel like phoning in to say that I cannot make it, I'm sick....I cannot, you know, take it.

........You know your people do not turn up for work.

Families of patients become secondary victims of stress as they observe their family members suffer. The lack of communication and respect was a frequently cited concern of most CCNs. You are there with the patient, the nursing staff, 24 hours, so I mean you are very important. The key factor of that 
However there were also positive comments:

Doctors in critical care treat nurses with respect because of their competency and skills.

When there is a higher level of competence involved there is a better relationship with the doctors.

\section{Solutions for enhancing critical care nurses' coping skills}

Debriefing and counselling could help CCNs to cope better with their stressful job-related situations. Providing debriefing sessions at regular intervals, but specifically after the death of a patient, could enhance CCNs resilience and coping abilities.

Adequate numbers of knowledgeable nurses in these units would decrease the CCNs stresses. Support and acknowledgement from nurse managers and from doctors would also ameliorate some stresses.

\section{Conclusions}

The major stress-related factors in the ICUs concerned shortages of knowledgeable nurses, absenteeism, doctors' demands, lack of support from management and from colleagues, and the stress caused by temporary nurses acquired from nursing agencies.

\section{Limitations}

The nature and size of the participants limit the potential to generalise the results of this research. The majority of the participants were females. Participants of both sexes, different cultural groups and various geographical areas would have been more representative of the population of CCNs in South Africa.

\section{Recommendations}

CCNs need more than simple stress management techniques. Environmental resources need to combine with individual characteristics and environmental resources to overcome severe stress in the work environment. Recommendations of this research are presented with specific reference to nursing unit management, nursing education and nursing research.

Nursing unit management
Conscious awareness among

CCNs should be addressed

during CCNs' in-service

education programmes.

A formal communication system

between $\mathrm{CCNs}$ and nurse

managers should be established

to address critical

inconsistencies and shortages

of personnel as well as

equipment.

- The development,

implementation and evaluation

of a support and stress

management programme

synergistically with resilient

enhancing skills and

techniques could help CCNs to

cope better, and might

contribute to decreasing

numbers of CCNs leaving

critical care units, or even the

nursing profession altogether.

\section{Nursing education}

The following recommendations are made regarding nursing education:

- $\quad$ Guidelines facilitating conscious awareness among CCNs by adopting resiliency should be incorporated in the basic nursing curriculum, and expanded upon in the curriculum for $\mathrm{CCNs}$.

- Publications in journals, presentations at symposia, workshops and refresher courses for critical care nurse managers, health care workers and counsellors should address ways of enhancing resiliency and conscious awareness.

- Empower nurse educators/ mentors and preceptors about resiliency.

\section{Nursing research}

The following recommendations are made regarding further research:

- This qualitative research only included CCNs working in private hospitals in Pretoria. Guidelines for enhancing CCNs' resiliency, hardiness and conscious awareness should be designed, evaluated, validated and refined further through extensive research by including other categories of nursing personnel in a variety of settings.

The implementation of these measures could help CCNs to cope better, reduce turnover rates, enhance the quality of nursing care received by the critically ill patients, and reduce costs to patients, ICUs and hospitals.

\section{References}

APPLETON, $L$ 1994: What is a critical incident? Canadian Nurse. 90(8):23-27.

BAILEY, RD 1985: Coping with stress in caring. London: Blackwell Science.

BAUM, A 1994: Stress, intrusive imagery and chronic distress. Health Psychologv. 49(12):653-664.

BELL, JL 1995: Traumatic event debriefing, severe debriefing designs and the role of social work. National Association of Social Workers. 40(1):3641.

BOSEK DE WOLF, MS 1999: Ethics in practice. Journal of the Nurses Association in Health Care Law. Ethics and Recuperation. 1(1):12-13.

BRINK, HIL 1996: Fundamentals of research methodology for health professionals. Kenwyn: Juta.

BURNS, N \& GROVE, SK 1999: Understanding nursing research. $2^{\text {nd }}$ edition.Philadelphia: WB Saunders.

CLOCHESY, JM; BREU, C; CARDIN, S, RUDY, EB \& WHITTAKER, AA 1996: Critical care nursing. $2^{\text {nd }}$ edition. Pennsylvania: WB Saunders.

CONCISE OXFORD HANDY DICTIONARY. 1991: London: Oxford University Press.

CRESSWELL, JW 1994: Research design: qualitative and quantitative approaches. London: Simon \& Shuster.

CUDMORE, J 1996: Preventing posttraumatic stress disorder in accident and emergency nursing. Nursing in Critical Care, 1(3):120-125.

EVERLY, GS \& LATING, JM 1995:

Psycho-traumatology: key papers and core concepts in post traumatic stress. New York: Plenum.

FINNEGAN, AP 1998: Clinical assessment for post traumatic stress disorder. British Journal of Nursing. 7(4): 212-218. 
GOLL-McGEE, B 1999: The role of the clinical forensic nurse in critical care. Nursing Ouarterly. 22(1):8-18.

ORASANO, JM \& BACHER, PI 1996: Stress in military performance in Stress and human performance edited by JE Driskell \& E Salas. Mahwah: Lawrence Erlbaum.

GUBA, EG \& LINCLOLN, YS 1985 Naturalistic inquiry. London: Sage.

HERMAN, JL 1992: Trauma and recovery: from domestic abuse to political terror. London: Harper Collins.

IVEY, AE; IVEY, MB \& SIMEKMORGAN, L 1997: Counseling and psychotherapy: a multicultural perspective. $4^{\text {th }}$ edition. Boston: Allan \& Bacon.

LAZARUS, RS \& FOLKMAN, S 1984: Stress, appraisal and coping. New York: Springer.

LAWS, T \& HAWKINS, C 1995: Critical incident stress. Australian Nursing Journal, 2(7): 17-18; 32-33.

MASLACH, C \& SCHAUFELI, WB 1993: Historical and conceptual development of burnout: recent developments in theory and research edited by WB Schaufeli, C Maslach \& T Marek. Washington DC: Taylor \& Francis.

MONSEN, RB; FLOYD, RB \& BROOKMAN, JC 1992: Stress-CopingAdaptation: concepts for nursing. Nursing Forum. 27(4):28.

MOUTON, J \& MARAIS, HC 1990: Basic concepts in the methodology of the social sciences. Pretoria: Human Sciences Research Council.

MULDARY, TW 1983: Burnout and health professionals: manifestations and management. Connecticut: AppletonCentury-Crofts.

NEUMAN, B 1995: The Neuman Systems Model. $3^{\text {rd }}$ edition. Norwalk: Appleton \& Lange.

PARAHOO, K 1997: Nursing research: principles, process and issues. London: MacMillan. fatigue. Journal of Medicine Practice.
7(4):39.

POLIT, DE \& HUNGLER, BP 1993: Essentials of nursing research methods, appraisals and utilisation. Philadelphia: JB Lippincot.

POLLARD, E 1994: The Oxford Paperback Dictionary. Oxford University Press.

RUTTER, M 1985: Resilience in the face of adversity. British Journal of Psychologv. 147:598-611.

SELYE, H 1974: Stress without distress. Philadelphia: JB Lippincott.

STRAUSS, A \& CORBIN, J. 1990: Basics of qualitative research: grounded theory procedures and techniques. London: Sage.

STRUMPHER, DJW 1995: The origins of health and strength from "salutogenisis" to "fortigenesis". South African Journal of Psychology. 25(2):2,19,65 81-89.

TAYLOR, G 1999: The race for consciousness: a Bradford book. Massachusets: MIT Press.

VAN SERVELLEN, G \& LEAKE, $B$. 1993: Burnout in hospital nurses: a comparison of acquired immunodeficiency syndrome, oncology, general medical and intensive care unit samples. Iournal of Professional Nursing. 9(3):169177.

WILKINSON, J 1999: Implementing reflective practice. Nursing Standard. 13(21): 37-39. 